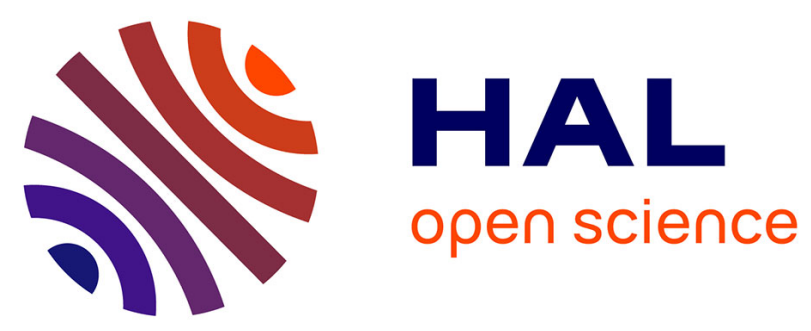

\title{
Ferroelectric polarization switching induced from water adsorption in BaTiO 3 ultrathin films
}

Pierre-Marie Deleuze, Bruno Domenichini, Céline Dupont

\section{To cite this version:}

Pierre-Marie Deleuze, Bruno Domenichini, Céline Dupont. Ferroelectric polarization switching induced from water adsorption in BaTiO 3 ultrathin films. Physical Review B: Condensed Matter and Materials Physics (1998-2015), 2020, 101, pp.075410. 10.1103/PhysRevB.101.075410 . hal-03022489

\section{HAL Id: hal-03022489 \\ https://hal.science/hal-03022489}

Submitted on 24 Nov 2020

HAL is a multi-disciplinary open access archive for the deposit and dissemination of scientific research documents, whether they are published or not. The documents may come from teaching and research institutions in France or abroad, or from public or private research centers.
L'archive ouverte pluridisciplinaire HAL, est destinée au dépôt et à la diffusion de documents scientifiques de niveau recherche, publiés ou non, émanant des établissements d'enseignement et de recherche français ou étrangers, des laboratoires publics ou privés. 


\title{
Ferroelectric polarization switching induced from water adsorption in $\mathrm{BaTiO}_{3}$ ultrathin films.
}

\author{
Pierre-Marie Deleuze, Bruno Domenichini, and Céline Dupont \\ Laboratoire Interdisciplinaire Carnot de Bourgogne (ICB), \\ UMR 6303 CNRS, Université de Bourgogne Franche Comté, \\ BP 47870, 21078 Dijon Cedex, France
}

(Dated: January 14, 2020)

\begin{abstract}
The influence of water on the out-of-plane polarization of $\mathrm{BaTiO}_{3}$ (BTO) ultrathin films is studied by means of density functional theory calculations. The adsorption is investigated for different coverages on both terminations of BTO with, for each case, all possible states of polarization, namely paraelectric, polarized upward or polarized downward. We thus demonstrate different behavior as a function of the termination. While $\mathrm{H}_{2} \mathrm{O}$ adsorbs only dissociatively on the $\mathrm{BaO}$ termination, with a reinforced interaction compared to BTO without out-of-plane polarization, only molecular adsorption is observed on the $\mathrm{TiO}_{2}$ termination. Besides, the presence of water is able to switch the polarization. Whatever the initial state of polarization, water induces a downward state on the $\mathrm{BaO}$ termination and an upward polarization on the $\mathrm{TiO}_{2}$ one. A detailed analysis of this phenomenon is given.
\end{abstract}




\section{INTRODUCTION}

Among the wide family of metal oxides, ferroelectric materials have lately concentrated a lot of attention as potential photocatalysts ${ }^{1-3}$. Indeed, their permanent intrinsic polarization allows to properly align bands instead of using an external electric bias, and enables photocarriers separation, limiting electron-hole recombination, one of the major drawbacks of oxides ${ }^{4}$. However, the existence of polarization cannot be neutral in reaction conditions. In particular the influence of polarization on the interaction of molecules with ferroelectric surfaces has been widely studied. The case of $\mathrm{P}^{+}$and $\mathrm{P}^{-}$surfaces of $\operatorname{LiNbO}_{3}(0001)$ has been considered both experimentally ${ }^{\frac{516}{6}}$ and theoretically ${ }^{\sqrt{78}}$ for their interaction with either $\mathrm{H}_{2} \mathrm{O}, \mathrm{CH}_{3} \mathrm{OH}$ or $\mathrm{H}$ and $\mathrm{OH}$ radicals. In all of these cases, different interactions have been evidenced depending on the $\mathrm{P}^{+}$or $\mathrm{P}^{-}$surface. Other classical ferroelectrics like $\mathrm{BaTiO}_{3}{ }^{9}[11$, $\mathrm{Pb}\left(\mathrm{Zr}_{0.8} \mathrm{Ti}_{0.2}\right) \mathrm{O}_{3}{ }^{9}$ or $\mathrm{PbTiO}_{3}{ }^{12}$ have been studied with always the same conclusions: there is a correlation between the oxide polarization and the surface interactions. This difference of behavior as a function of the polarization has opened the door to switchable chemistry 3113 . In fact, by imposing an external potential able to switch from $\mathrm{P}^{+}$to $\mathrm{P}^{-}$, or conversely, one can take benefit of the physical and chemical properties of each surface. Beyond the electrical switching, the chemical switching has been firstly evidenced in 2009 by Wang et al. for $\mathrm{PbTiO}_{3}$ in presence of $\mathrm{O}_{2}{ }^{14}$. Following this paper, several studies ${ }^{15}$ have focused on the surface charge screening potentially leading to a reversal of the surface dipole. Despite the great importance of this phenomenon and potential applications, up to now there is no study describing the interaction of water with one of the most important ferroelectric materials, $\mathrm{BaTiO}_{3}$ (BTO) presenting an out-of-plane polarization. Theoretically, only studies ${ }^{20-22}$ describing water adsorption on in-plane polarized $\mathrm{BaTiO}_{3}$ have been conducted.

Thus, in this paper we endeavour to thoroughly describe the interaction of $\mathrm{H}_{2} \mathrm{O}$ with both $\mathrm{TiO}_{2}$ and $\mathrm{BaO}$ terminations of out-of-plane polarized ultrathin $\mathrm{BaTiO}_{3}$.

\section{COMPUTATIONAL DETAILS}

Calculations were performed in the framework of Density Functional Theory (DFT) using the Vienna ab initio simulation package VASP code 2324 . Because the long-range van der Waals interactions play an important part in the interaction between water and the 
$\mathrm{BaTiO}_{3}$ surface, calculations were made using the dispersion corrected density functional theory (DFT-D3) $)^{25}$. The electronic-exchange correlation potential was treated using the generalized gradient approximation (GGA) with Perdew-Burke-Ernzerhof $(\mathrm{PBE})^{26}$ functional. Pseudopotentials of projector augmented wave $(\mathrm{PAW})^{2728}$ were employed and included ten valence electrons for $\mathrm{Ba}\left(5 \mathrm{~s}^{2} 5 \mathrm{p}^{6} 4 \mathrm{~s}^{2} 3 \mathrm{~d}^{2}\right)$, six for $\mathrm{O}\left(2 \mathrm{~s}^{2} 2 \mathrm{p}^{4}\right)$ and twelve for $\mathrm{Ti}\left(3 \mathrm{~s}^{2} 3 \mathrm{p}^{6} 4 \mathrm{~s}^{2}\right.$ $\left.3 \mathrm{~d}^{2}\right)$. The plane wave energy cutoff was set to $500 \mathrm{eV}$. The Coulomb interaction $\mathrm{U}_{\text {eff }}=3.5$ $\mathrm{eV}$ was applied on Ti $3 \mathrm{~d}$ electrons.

The tolerance of total energy convergence was set to $10^{-6} \mathrm{eV}$. The structural relaxation was carried on until all the forces on the atoms converge below $0.01 \mathrm{eV} / \AA$. In the following, different periodicities $(\mathrm{N})$ of unit cells have been considered to modify the water coverage; a $7 \times 7 \times 1$ Monkhorst-Pack ${ }^{299} k$-point mesh was used to sample the first Brillouin zone for the smallest periodicity $(\mathrm{N}=2)$. For larger cells, the grid was adapted accordingly.

BTO is often used deposited on a substrate like Pt. However, we calculated that, beyond the induced strain, the presence of the substrate has no influence on the water adsorption. Nevertheless, the presence of platinum is considered through the $2.1 \%$ compressive strain imposed on BTO by the lattice mismatch between Pt and BTO. Hence in the following, platinum is not implemented explicitly. However to support our choice, for each configuration of isolated strained BTO reported in this paper, the equivalent structure with explicit platinum substrate is reported in Supplementary Information. In the following, BTO surfaces are thus modeled by symmetric $\mathrm{TiO}_{2}$-terminated and $\mathrm{BaO}$-terminated surfaces of 11 layers, in which all atoms are free to relax, allowing a complete and free optimization of the slab polarization. This model corresponds to an ultrathin film with a thickness of $2.1 \mathrm{~nm}$ which has been evidenced as sufficient for the appearance of ferroelectricity, both experimentally $\sqrt{30131}$ and theoretically ${ }^{32}$. Besides, we checked that higher thickness leads to the same polarization patterns (see Figure SI1). A vacuum layer of $20 \AA$ is implemented to prevent any interactions between periodic images along the $z$ direction. The method used to model the out-of-plane polarization is extensively described elsewhere ${ }^{32}$. In summary, it follows Migoni's ${ }^{33}$ approach which consists in dividing the slab into two domains of opposite polarization, leading to an overall cell with no net dipole moment.

When a single water molecule is adsorbed on the surface, the adsorption energy is defined as :

$$
E_{a d s}=E\left(s l a b+\mathrm{H}_{2} \mathrm{O}\right)-E(s l a b)-E\left(\mathrm{H}_{2} \mathrm{O}\right)
$$




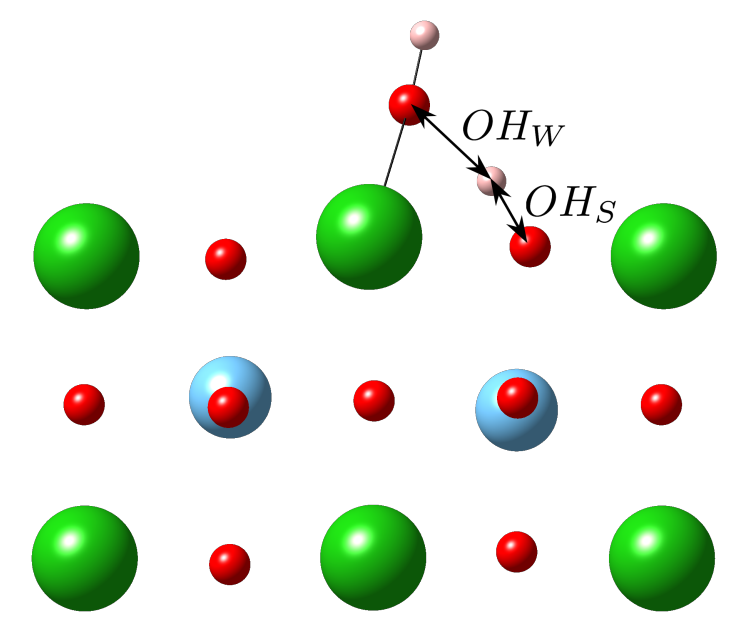

Figure 1. Sideview of the first three layers of $\mathrm{BaO}$-terminated slab with a water molecule adsorbed. Characteristic distances, $\mathrm{OH}_{W}$ and $\mathrm{OH}_{S}$ are represented. Ba atoms are reported in green, Ti atoms in blue, oxygen atoms in red and hydrogen atoms in white.

where $E\left(s l a b+\mathrm{H}_{2} \mathrm{O}\right)$ is the total energy of the optimized slab with one water molecule adsorbed, $E(s l a b)$ is the total energy of the optimized paraelectric slab without water, $E\left(\mathrm{H}_{2} \mathrm{O}\right)$ is the total energy of the free water molecule. Therefore, a negative value of $E_{a d s}$ means that the adsorption is favorable.

When two water molecules are adsorbed, depending on the nature of the adsorption, both adsorption energies are either treated separately or the average adsorption energy is considered. In the first case, the adsorption energy of the first molecule is calculated with equation (1) and the value is referred to as $E_{a d s}^{1}$. The adsorption energy of the second molecule is calculated as :

$$
E_{a d s}^{2}=E\left(s l a b+2 \mathrm{H}_{2} \mathrm{O}\right)-E\left(s l a b+\mathrm{H}_{2} \mathrm{O}\right)-E\left(\mathrm{H}_{2} \mathrm{O}\right)
$$

where $\mathrm{E}\left(\mathrm{slab}+2 \mathrm{H}_{2} \mathrm{O}\right)$ is the total energy of the optimized slab with two water molecules adsorbed, $E\left(s l a b+\mathrm{H}_{2} \mathrm{O}\right)$ is the total energy of the optimized slab with a single water molecule and $E\left(\mathrm{H}_{2} \mathrm{O}\right)$ is the total energy of the free water molecule.

In the following, the length of the elongated $\mathrm{O}-\mathrm{H}$ of the water molecule is called $O H_{W}$ while the distance between the surface oxygen and the hydrogen of the water molecule is named $\mathrm{OH}_{S}$, as described on Figure 1 


\section{RESULTS}

\section{A. Adsorption modes}

\section{BaO termination}

The adsorption of water is first considered on the $\mathrm{BaO}$ termination, for coverages ranging from $1 / 8$ to $1 / 2$ monolayer (ML). All stable configurations are named as follows: $X_{\theta}^{N}$ where $\theta$ refers to the coverage $(1 / 8,1 / 4$ or $1 / 2$ in ML), $N$ refers to the periodicity ( 2 or 4 unit cells) and $\mathrm{X}$ allows to differ configurations of same $\theta$ and $\mathrm{N}$ and takes values $\mathrm{A}, \mathrm{B}, \mathrm{C}, \ldots$ For the lowest coverage $(1 / 8 \mathrm{ML})$ one water molecule is adsorbed in a cell with a lateral periodicity of four unit cells $(\mathrm{N}=4)$. As an initial state, different geometrical configurations of the water molecule are combined with different states of polarization, namely the paraelectric slab, the upward and the downward polarized part of the slab. Figure 2 shows the obtained two stable configurations, while their corresponding adsorption energies are reported in Table I. For the sake of clarity, only the three upper cells are reported, while the whole simulation cell composed of five unit cells is represented in Supplementary Information. As shown on Figure 2, the final state always presents a downward polarization regardless of the initial polarization. These important findings will be discussed in details further.

In both cases, water spontaneously dissociates into a $\mathrm{H}^{+}$which bonds with a surface oxygen and a hydroxyl group that binds between two Ba either in the (100) or (010) plane (see Figure 2), referred to as $A_{1 / 8}^{4}$ and $B_{1 / 8}^{4}$ with adsorption energies of -1.15 and $-1.12 \mathrm{eV}$, respectively. In the following, whatever the coverage, the adsorption with a configuration similar to $A_{1 / 8}^{4}$ will be referred as Mode 1 , while adsorption similar to $B_{1 / 8}^{4}$ will be called Mode 2. In $A_{1 / 8}^{4}$, the $O H_{S}$ distance is $1.05 \AA$ and $O H_{W}$ is $1.48 \AA$ while in $B_{1 / 8}^{4} O H_{S}$ and $O H_{W}$ are $1.02 \AA$ and $1.57 \AA$, respectively. These findings compare very well with previous results. In fact, our $A_{1 / 8}^{4}$ configuration corresponds to the dissociative adsorption observed by Geneste et al. ${ }^{20}$, without out-of-plane polarization. Nevertheless, they obtained a lower adsorption energy of $-0.77 \mathrm{eV}$. If our higher adsorption can be partially explained by our level of calculation (we have included dispersion corrections which reinforce hydrogen bonds), this correction is not sufficient to justify the difference of $0.35 \mathrm{eV}$. Indeed, without dispersion corrections, the adsorption energy of $A_{1 / 8}^{4}$ is reduced from -1.12 to $-0.98 \mathrm{eV}$, a value still 0.21 $\mathrm{eV}$ higher than the one on BTO without out-of-plane polarization. Hence, the out-of-plane 

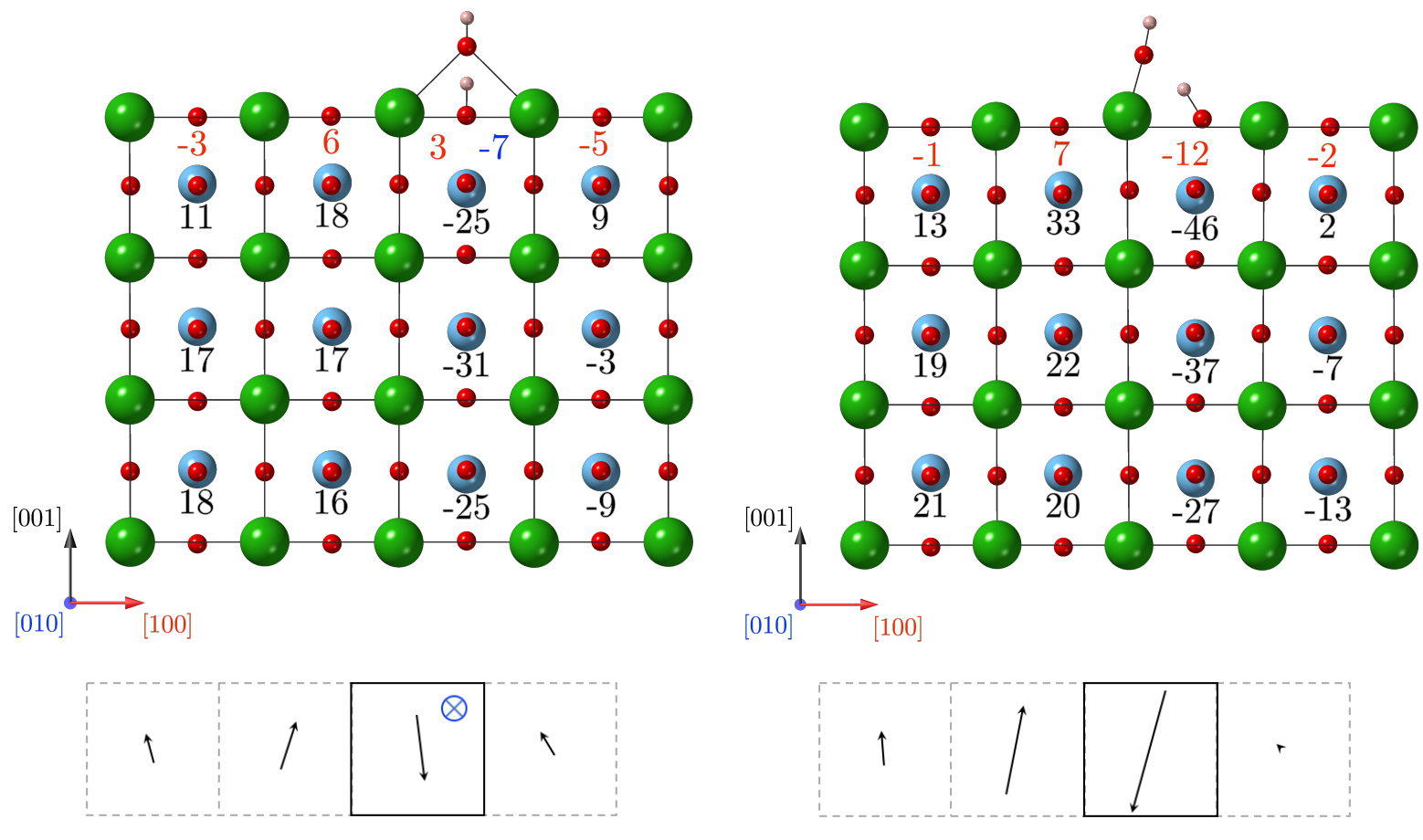

$A_{1 / 8}^{4}$

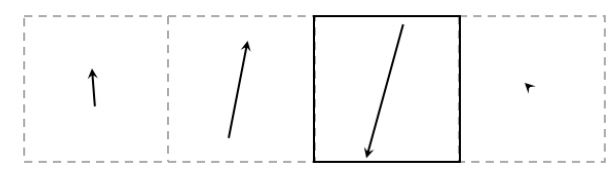

$B_{1 / 8}^{4}$

Figure 2. (Top) Sideviews of the most stable structures of the BaO-terminated surface with a four unit cell periodicity $(\mathrm{N}=4)$ for a $\frac{1}{8} \mathrm{ML}$ adsorption. Only the first seven layers are represented. The values in black, blue and red indicate the polarization in $\mu \mathrm{C} / \mathrm{cm}^{2}$ in each unit cell along the [001], [010] and [100] directions, respectively. Only non zero polarization are printed. See Figure SI 2 for the representation of the whole simulation cell. (Bottom) Vectorial representation of the polarization in the cells of the first layer. Cells with water adsorbed on their surface are represented in plain lines, while cells without water are in dotted lines. Blue circled cross or dot indicates the existence and direction of polarization along the [010] axis.

polarization clearly reinforces the interaction between water and BTO. This can also explain why we only observe dissociated water on the $\mathrm{BaO}$ termination, while previous studies2021, without out-of-plane polarization nor inclusion of dispersion, were able to stabilize molecular $\mathrm{H}_{2} \mathrm{O}$ on $\mathrm{BaO}$. In this spirit, the molecular adsorption state found by Geneste et al. ${ }^{[20}$ with an adsorption energy of $-0.72 \mathrm{eV}$ can be seen as a precursor of our dissociated $B_{1 / 8}^{4}$ configuration.

The coverage was then increased to $1 / 4 \mathrm{ML}$ in two different ways: either by adding a second molecule to the 1/8 ML case or by considering a single water molecule in a cell 


\begin{tabular}{|c|c|c|c|c|}
\hline Coverage & Periodicity & Configuration & $E_{a d s}^{1}$ & $E_{a d s}^{2}$ \\
\hline \multirow{2}{*}{$\frac{1}{8} \mathrm{ML}$} & \multirow{2}{*}{$\mathrm{N}=4$} & $A_{1 / 8}^{4}$ & -1.12 & - \\
\hline & & $B_{1 / 8}^{4}$ & -1.15 & - \\
\hline \multirow{9}{*}{$\frac{1}{4} \mathrm{ML}$} & \multirow{2}{*}{$\mathrm{N}=2$} & $A_{1 / 4}^{2}$ & -1.09 & - \\
\hline & & $B_{1 / 4}^{2}$ & -1.08 & - \\
\hline & \multirow{7}{*}{$\mathrm{N}=4$} & $A_{1 / 4}^{4}$ & \multicolumn{2}{|c|}{-1.07} \\
\hline & & $B_{1 / 4}^{4}$ & \multicolumn{2}{|c|}{-1.08} \\
\hline & & $C_{1 / 4}^{4}$ & \multicolumn{2}{|c|}{-1.04} \\
\hline & & $D_{1 / 4}^{4}$ & \multicolumn{2}{|c|}{-1.09} \\
\hline & & $E_{1 / 4}^{4}$ & -1.15 & -0.95 \\
\hline & & $F_{1 / 4}^{4}$ & -1.12 & -0.96 \\
\hline & & $G_{1 / 4}^{4}$ & -1.15 & -0.97 \\
\hline \multirow{3}{*}{$\frac{1}{2} \mathrm{ML}$} & \multirow{3}{*}{$\mathrm{N}=2$} & $A_{1 / 2}^{2}$ & -1.09 & -0.90 \\
\hline & & $B_{1 / 2}^{2}$ & -1.08 & -0.96 \\
\hline & & $C_{1 / 2}^{2}$ & -1.09 & -0.79 \\
\hline
\end{tabular}

Table I. Water adsorption energies in $\mathrm{eV}$ on $\mathrm{BaO}$ termination as a function of the water coverage. As previously described, $E_{a d s}^{1}$ refers to the adsorption energy of the first water molecule and $E_{a d s}^{2}$ to the addition of a second water molecule. When both water molecules are equivalent, only the average adsorption energy is given.

with a lateral periodicity of two unit cells $(\mathrm{N}=2)$. The latter case is very similar to the 1/8 ML coverage already discussed. Obtained configurations are reported on Figure 3 and adsorption energies in Table I. The only difference with $\theta=1 / 8$ ML lies on the adsorption energy, which is a bit reduced for this higher coverage: values of -1.09 and $-1.08 \mathrm{eV}$ are obtained at $\theta=1 / 4 \mathrm{ML}$, instead of -1.15 and $-1.12 \mathrm{eV}$, respectively for $\theta=1 / 8 \mathrm{ML}$, as a consequence of lateral interactions. For $\theta=1 / 4 \mathrm{ML}$ obtained through the adsorption of two water molecules in the larger cell $(\mathrm{N}=4)$, there are more cases: the second molecule can be added either on the same unit cell as the first one, or on another unit cell, adjacent or not. The most stable configurations can be divided in two categories depending on whether the second molecule dissociates (Figure 44) or not (Figure 5). The obtained results suggest that water is more inclined to dissociate as previously observed ${ }^{21}$. Nevertheless, the adsorption 

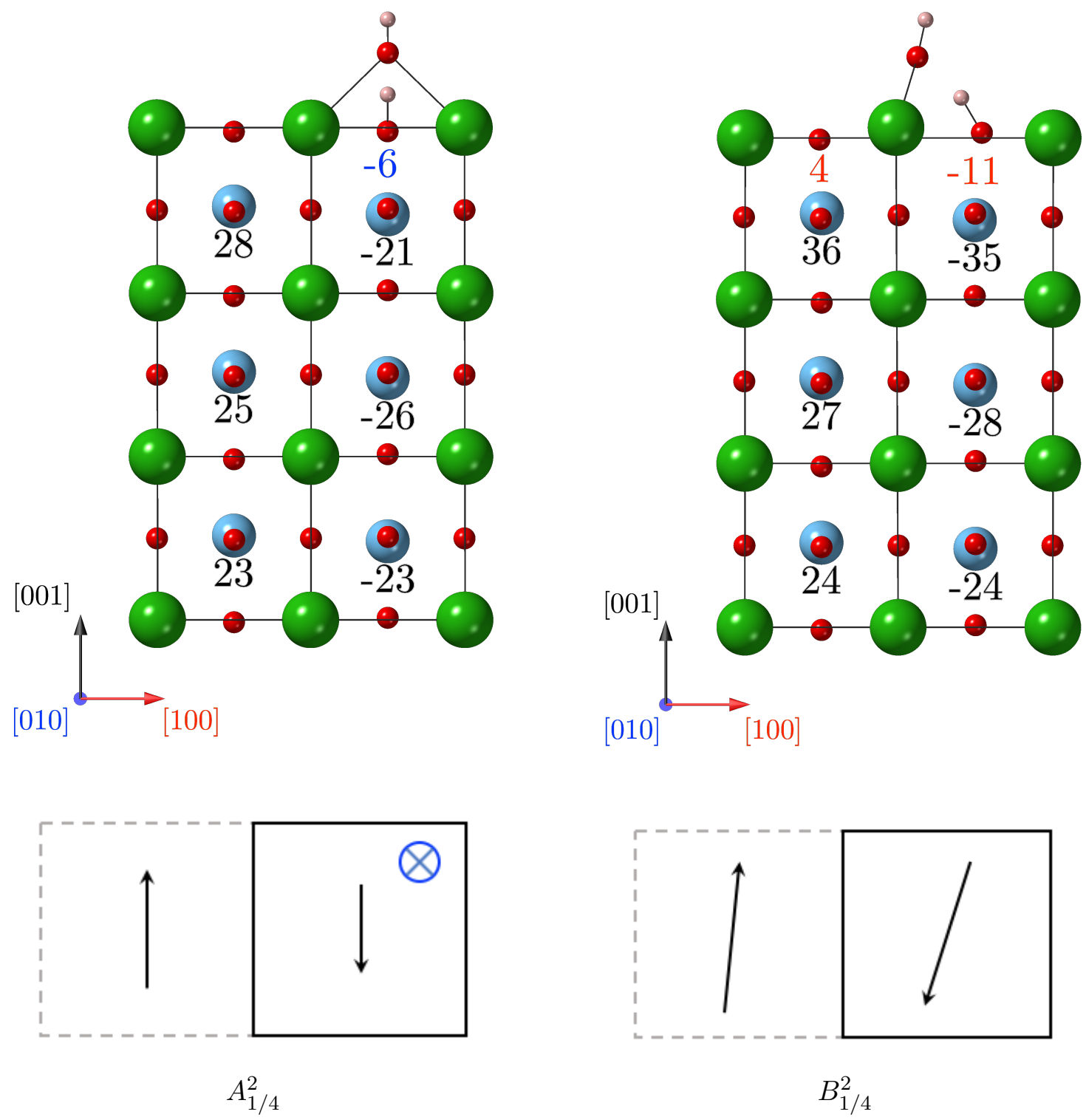

Figure 3. Most stable structures of the BaO-terminated surface with $\mathrm{N}=2$ and $\theta=\frac{1}{4} \mathrm{ML}$. See Figure SI 3 for the representation of the whole simulation cell.

energies in the mixed adsorption structures are very close, so each configuration is likely to exist. If the second water molecule adsorbs on the surface without interacting with the first one, it spontaneously dissociates in the same geometry as the previously observed structures (Mode 1 and Mode 2). In the mixed adsorption case (see Figure 5), the second water molecule maintains its molecular state and forms a hydrogen bond with the first water molecule. The length of the hydrogen bond is $1.59 \AA$ in $E_{1 / 4}^{4}$ and $1.52 \AA$ in $F_{1 / 4}^{4}$. This interaction causes the first molecule to be even more distorted. Indeed, in $E_{1 / 4}^{4} \mathrm{OH}_{W}$ stretches from 1.57 to 1.99 $\AA$ and from 1.48 to $1.65 \AA$ in $F_{1 / 4}^{4}$. Moreover, in $E_{1 / 4}^{4}$ the second water molecule through 

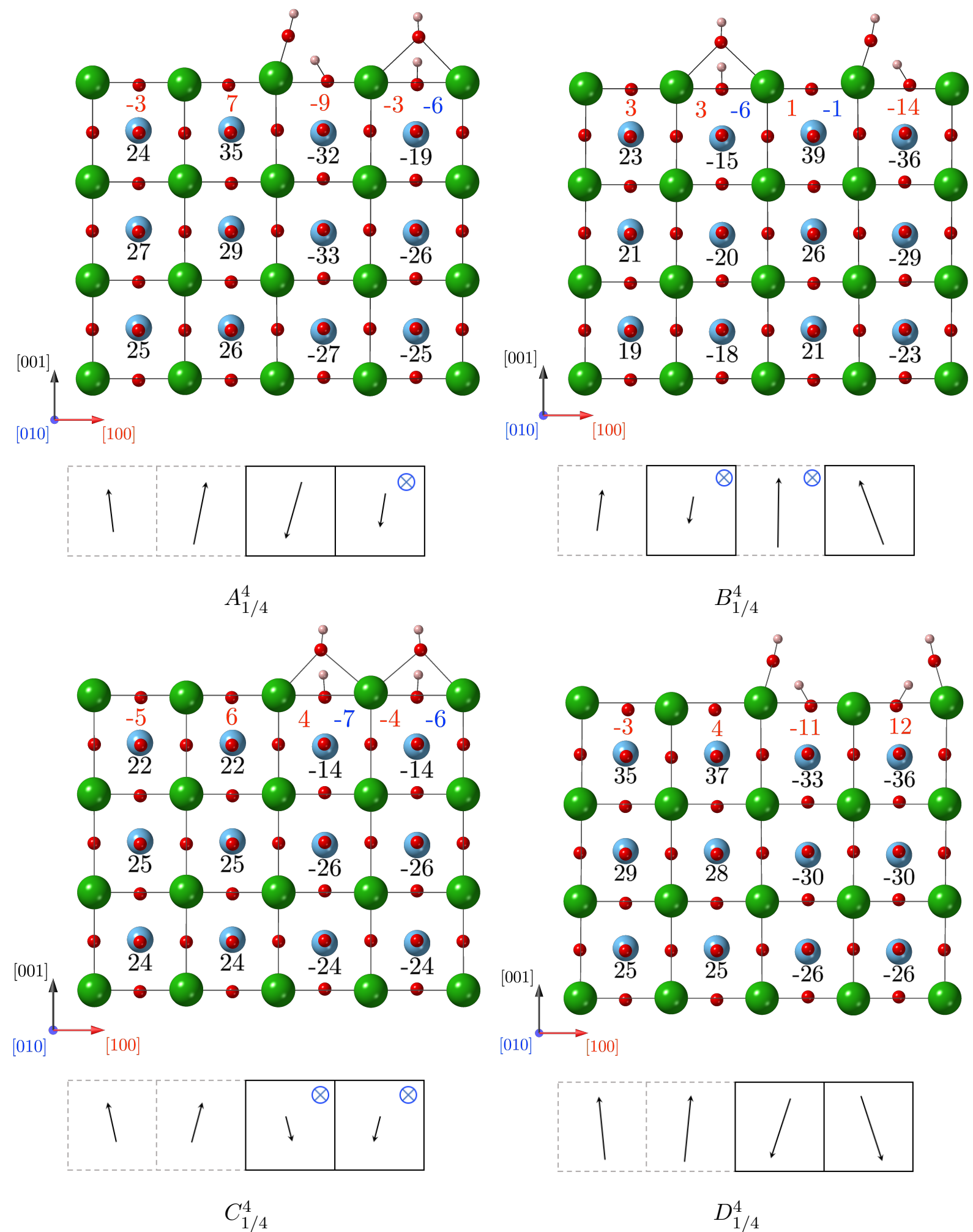

$D_{1 / 4}^{4}$

Figure 4. Most stable structures of dissociated water on the BaO-terminated surface with $\mathrm{N}=4$ and $\theta=\frac{1}{4}$ ML. See Figure SI 4 for the representation of the whole simulation cell. 

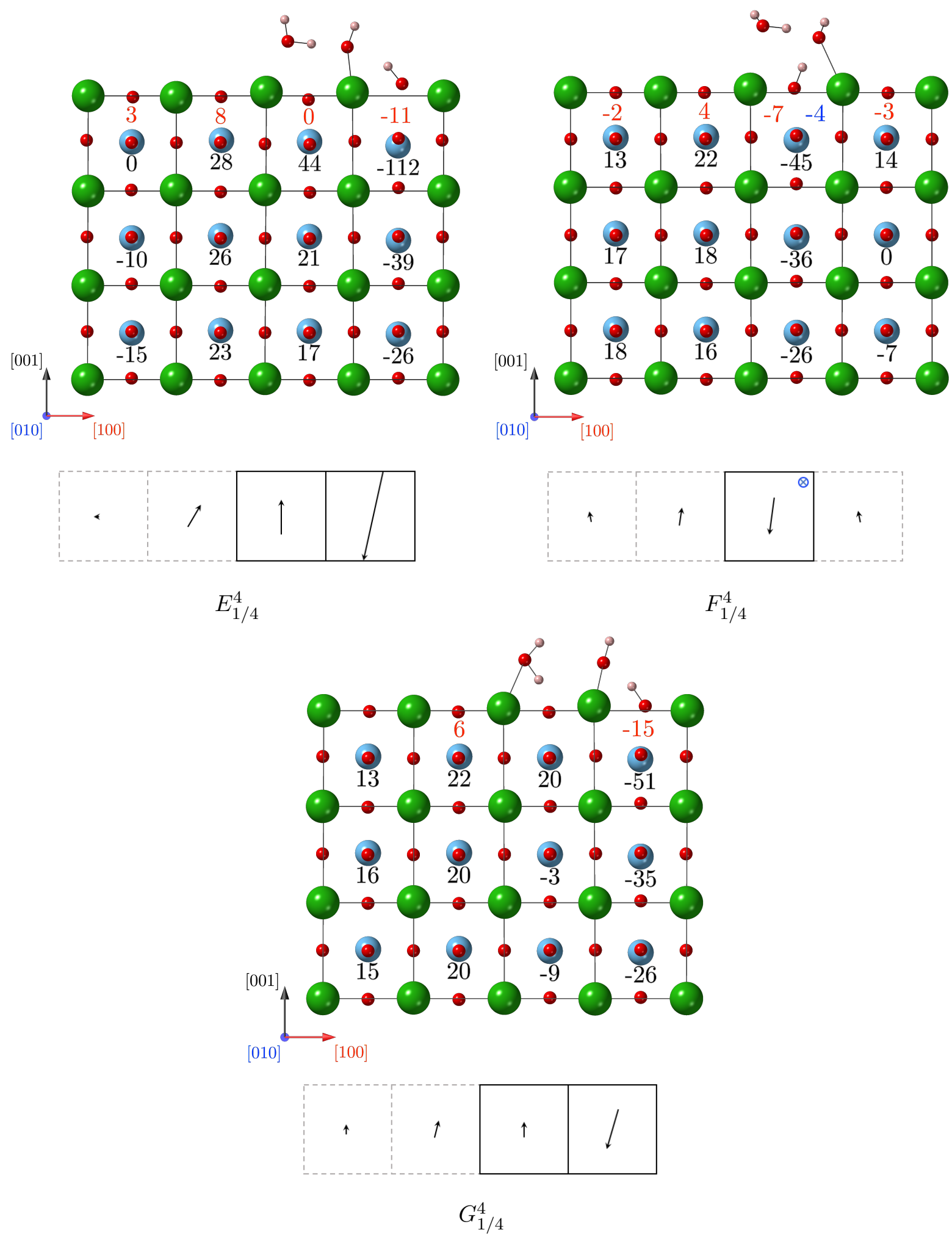

Figure 5. Most stable structures of the mixed adsorption cases on the BaO-terminated surface with $\mathrm{N}=4$ and $\theta=\frac{1}{4}$ ML. See Figure SI 5 for the representation of the whole simulation cell. 
the hydrogen bond pulls the first dissociated water molecule. Thus, the second hydrogen bond $\left(\mathrm{OH}_{W}\right)$ pulls the $\mathrm{O}$ ion out from the surface by $0.52 \AA$ which induces a very large out-of-plane polarization in the first surface layers. In $G_{1 / 4}^{4}$, the second water molecule is adsorbed in a configuration similar to Mode 2 but less bonded to the surface, leading to a non dissociated configuration. Hence, $\mathrm{d}(\mathrm{Ba}-\mathrm{O})$ is extended to $3.01 \AA$ instead of $2.71 \AA$, and $\mathrm{OH}_{S}$ is not a real O-H bond like in Mode 2, where $\mathrm{d}(\mathrm{O}-\mathrm{H})=1.02 \AA$, but a hydrogen bond of $1.47 \AA$.

Finally, the highest considered coverage is half a monolayer. To reach such a coverage, a second water molecule is added to $\theta=1 / 4 \mathrm{ML}$ in the $\mathrm{N}=2$ periodicity. Obtained structures are shown on Figure 6. In all cases, the second water molecule adsorbs molecularly on the surface. However, the adsorption is more favorable when both molecules are on the same downward polarized domain. In such case, the interaction between both molecules leads to a larger distortion of the first molecule as $O H_{W}$ stretches from 1.45 to $1.60 \AA$ in $A_{1 / 2}^{2}$ and from 1.52 to $1.61 \AA$ in $B_{1 / 2}^{2}$. This behavior was already observed by Li et al. when studying water adsorption on in-plane polarized $\mathrm{BTO}^{21}$.

\section{2. $\mathrm{TiO}_{2}$ termination}

Let us now discuss the behavior of water adsorption on the $\mathrm{TiO}_{2}$ termination. We consider the same coverages as before, with water initially adsorbed either on the upward or the downward polarized domain as well as on the paraelectric slab. On $\mathrm{TiO}_{2}$, whatever the starting polarization, only upward slab is obtained as a final state. This result will be discussed later. Obtained configurations are reported on Figures 7 and 8, with their corresponding energies in Table II.

Contrary to what occurs on $\mathrm{BaO}$, water adsorbs only molecularly on $\mathrm{TiO}_{2}$ without spontaneous dissociation, whatever the coverage. This indicates a weaker interaction with the $\mathrm{TiO}_{2}$ termination, confirmed by a lower adsorption energy of $-0.97 \mathrm{eV}$ instead of $-1.14 \mathrm{eV}$ on $\mathrm{BaO}$. This is in agreement with previous findings on in-plane polarized BTO 20121 , but also on $\mathrm{SrTiO}_{3}(001)^{34}$, meaning that out-of-plane polarization does not dramatically influence the adsorption modes.

At the highest coverage $(\theta=1 / 2 \mathrm{ML}$ - Figure 8), the second molecule can either adsorb on the same domain than the first one $\left(A_{1 / 2}^{2}\right)$ or on the oppositely polarized domain $\left(B_{1 / 2}^{2}\right)$. 

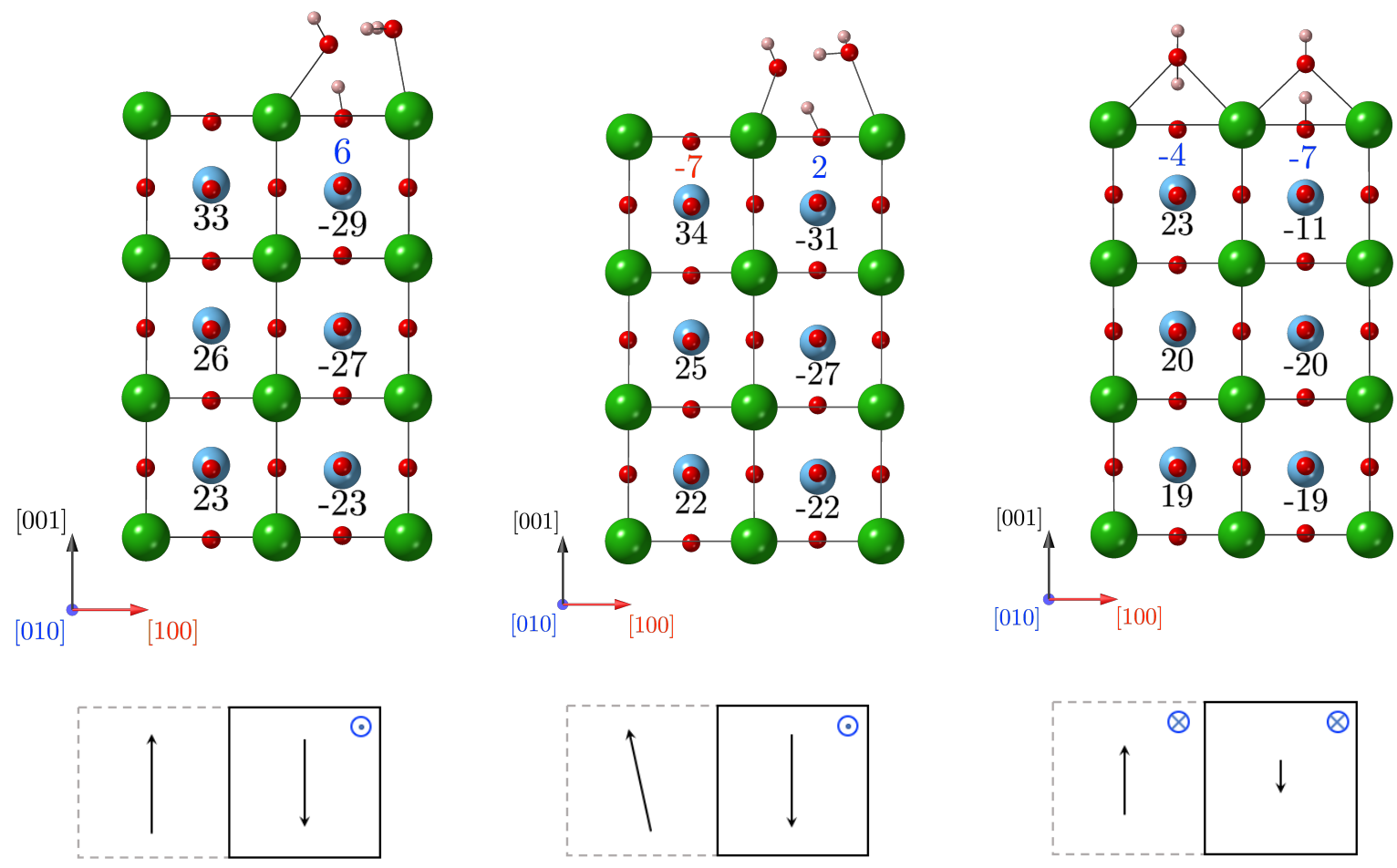

$A_{1 / 2}^{2}$

$B_{1 / 2}^{2}$

$C_{1 / 2}^{2}$

Figure 6. Most stable structures of the BaO-terminated surface with $\mathrm{N}=2$ and $\theta=\frac{1}{2} \mathrm{ML}$. See Figure SI 6 for the representation of the whole simulation cell.

\begin{tabular}{c|c|c|c|c} 
Coverage & Periodicity & Configuration & $E_{\text {ads }}^{1}$ & $E_{\text {ads }}^{2}$ \\
\hline$\frac{1}{8} \mathrm{ML}$ & $\mathrm{N}=4$ & $A_{1 / 8}^{4}$ & -0.98 & - \\
\hline \multirow{2}{*}{$\frac{1}{4} \mathrm{ML}$} & $\mathrm{N}=2$ & $A_{1 / 4}^{2}$ & -0.97 & - \\
\cline { 2 - 5 } & $\mathrm{N}=4$ & $A_{1 / 4}^{4}$ & \multicolumn{2}{|c}{-0.97} \\
\hline \multirow{2}{*}{$\frac{1}{2} \mathrm{ML}$} & $\mathrm{N}=2$ & $A_{1 / 2}^{2}$ & -0.97 & -0.99 \\
& & $B_{1 / 2}^{2}$ & \multicolumn{2}{|c}{-0.94}
\end{tabular}

Table II. Water adsorption energies in $\mathrm{eV}$ on $\mathrm{TiO}_{2}$ termination as a function of the water coverage.

In the former case, the second molecule adsorbs through two hydrogen bonds: one with the first molecule and a second with the surface oxygen at a distance of $1.43 \AA$ and $1.97 \AA$ respectively. The adsorption energy of the second water molecule is $-0.99 \mathrm{eV}$ in $A_{1 / 2}^{2}$, while the average adsorption energy in $B_{1 / 2}^{2}$ is $-0.97 \mathrm{eV}$, indicating that both configurations can exist, the single consequence being on the polarization and will be discussed in the following. 

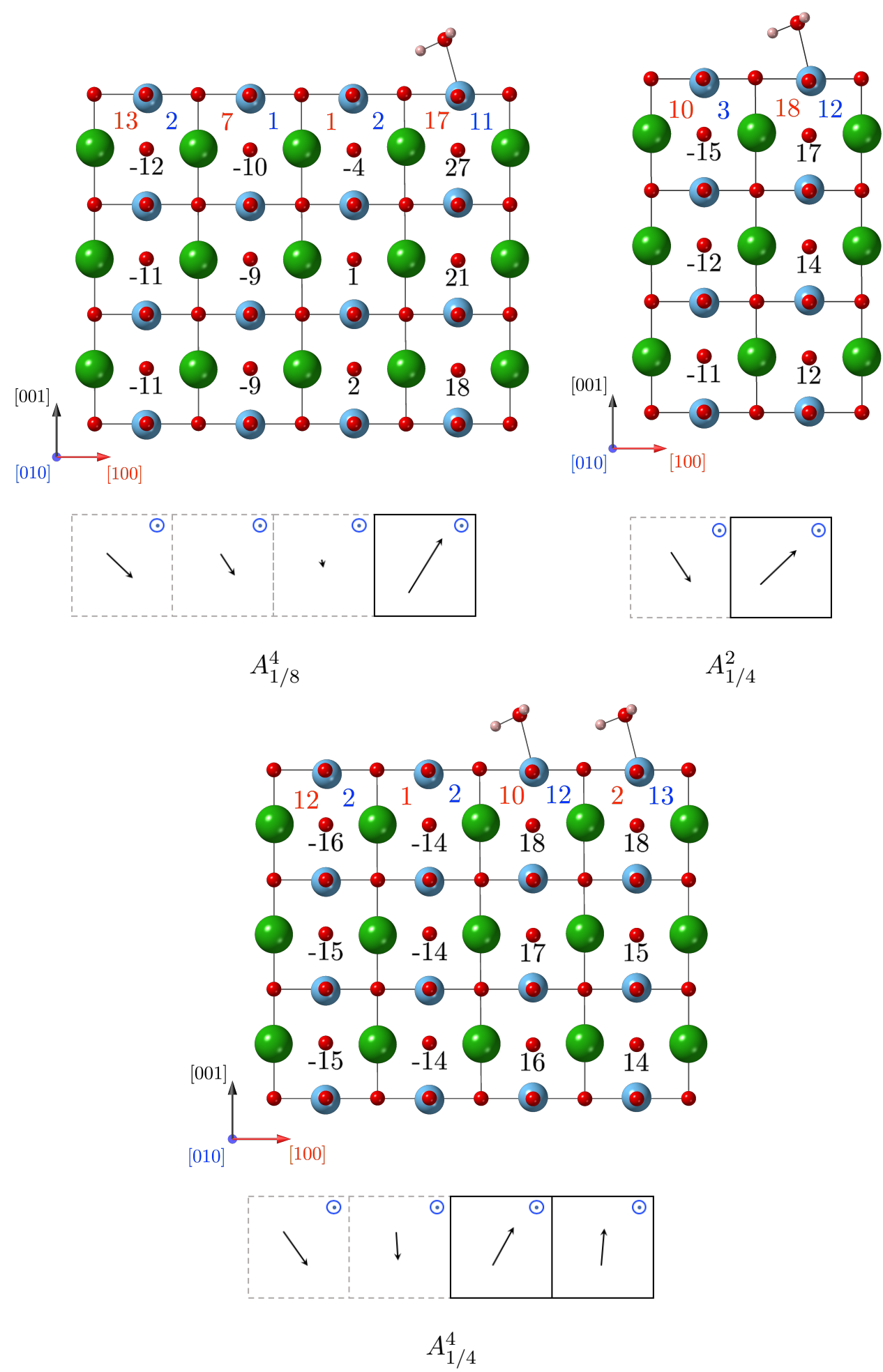

Figure 7. Most stable structure of the $\mathrm{TiO}_{2}$-terminated surface with $\mathrm{N}=4$ and $\theta=\frac{1}{8} \mathrm{ML}\left(A_{1 / 8}^{4}\right)$, with $\mathrm{N}=2$ and $\theta=\frac{1}{4} \mathrm{ML}\left(A_{1 / 4}^{2}\right)$ and with $\mathrm{N}=4$ and $\theta=\frac{1}{4} \mathrm{ML}\left(A_{1 / 4}^{4}\right)$. See Figure SI 7 for the representation of the whole simulation cell. 

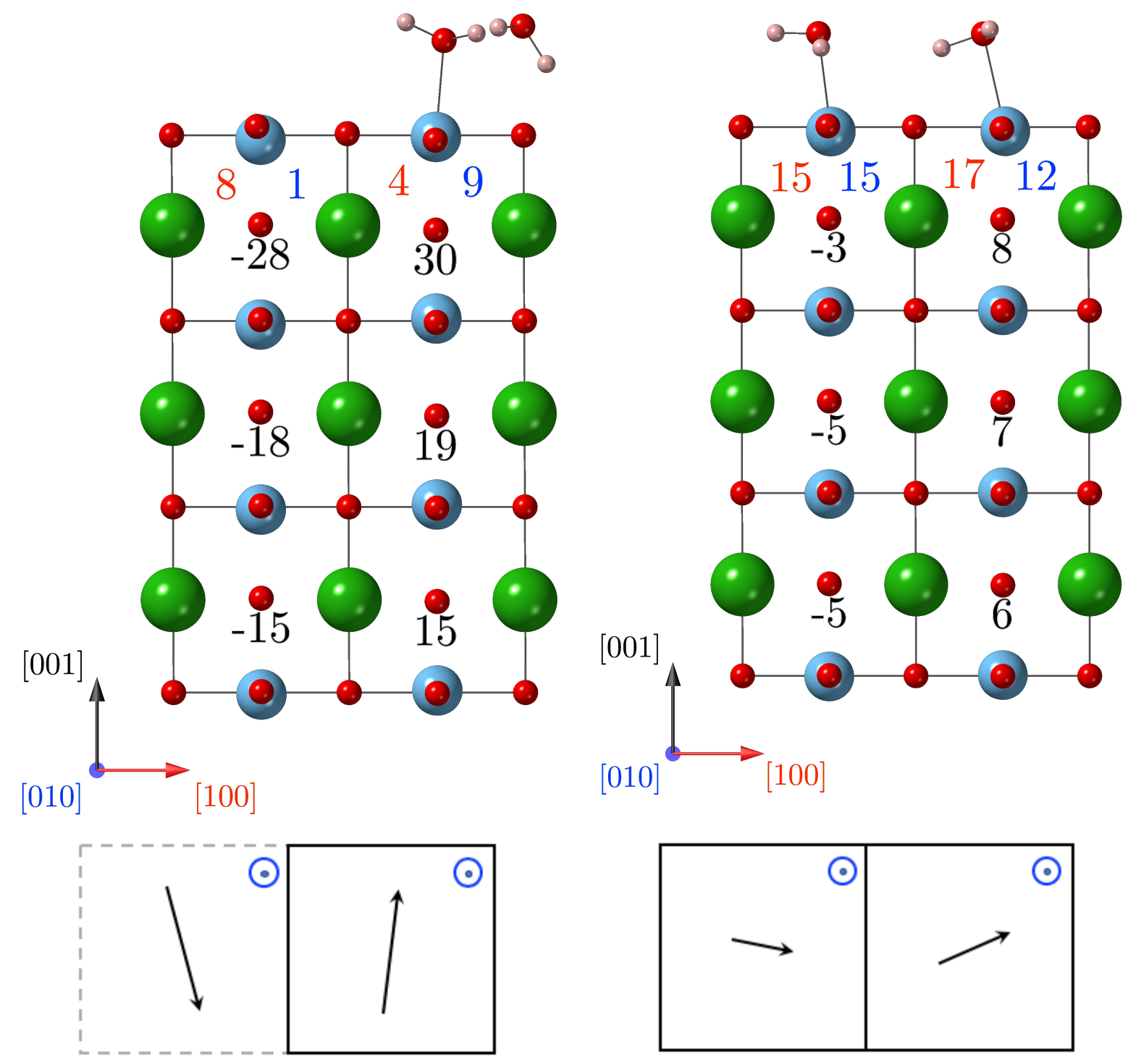

$A_{1 / 2}^{2}$

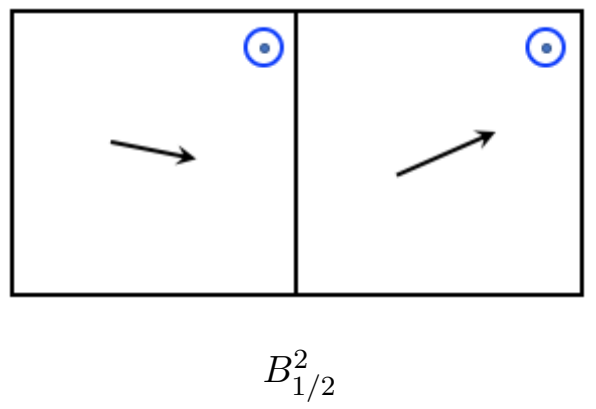

Figure 8. Most stable structures of the $\mathrm{TiO}_{2}$-terminated surface with $\mathrm{N}=2$ and $\theta=\frac{1}{2} \mathrm{ML}$. See Figure SI 8 for the representation of the whole simulation cell.

For the sake of completeness, even if water does not dissociate spontaneously, the dissociated adsorption has been studied for the intermediate coverage of $1 / 4 \mathrm{ML}$. The related configuration is reported on Figure 9. This dissociation creates two $\mathrm{OH}$ groups, both oriented in the [010] direction. The $\mathrm{OH}$ adsorbed on Ti pulls this Ti atom out of the surface by $0.61 \AA$. This induces large consequences on the polarization which will be discussed later. From the energetic point of view, this dissociated case presents an adsorption energy of -1.28 $\mathrm{eV}$, hence $0.3 \mathrm{eV}$ more stable than the molecular adsorption. The dissociation barrier was 


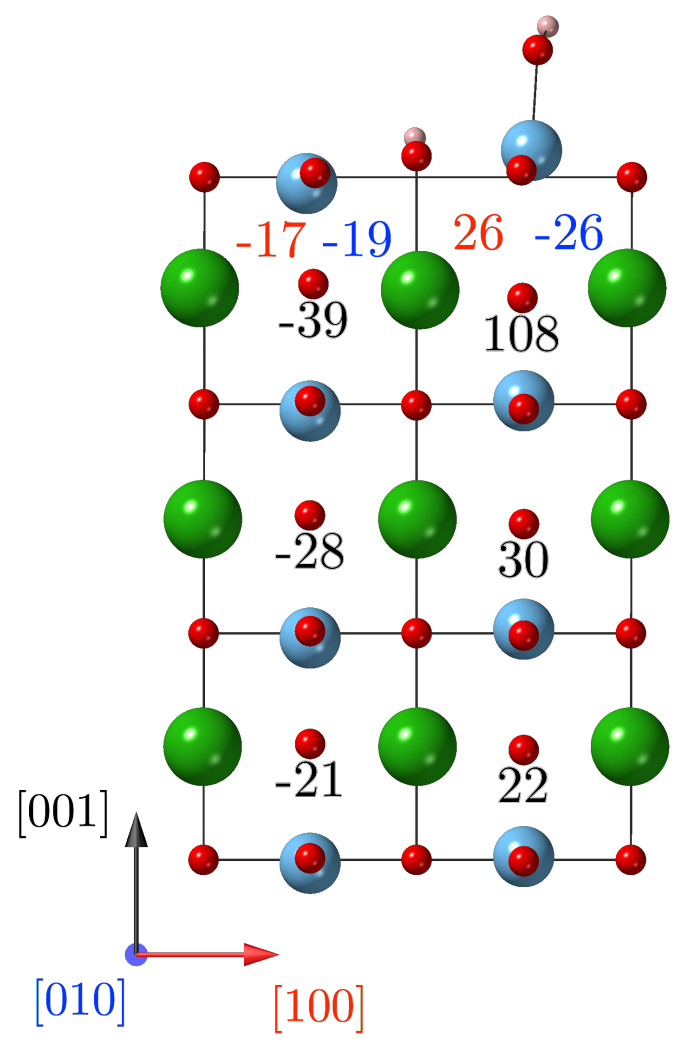

Figure 9. Sideview of the dissociative adsorption of water on the $\mathrm{TiO}_{2}$-terminated surface for $\mathrm{N}=$ 2 and $\theta=\frac{1}{4}$ ML. See Figure SI 9 for the representation of the whole simulation cell.

roughly estimated at $0.1 \mathrm{eV}$ through CI-NEB calculations ${ }^{35}$, meaning that in real conditions we will more probably observe dissociated $\mathrm{H}_{2} \mathrm{O}$.

\section{B. Polarization}

The influence of water adsorption on the polarization is now discussed in details. The first and also most important conclusion concerns the global polarization. In fact, whatever the initial state (paraelectric, polarized upward or downward) of the slab, in the presence of water, its final state is always $\mathrm{P}_{\text {down }}$ for the $\mathrm{BaO}$ termination and $\mathrm{P}_{\text {up }}$ for the $\mathrm{TiO}_{2}$ one. Thus, for $\mathrm{BaO}$, a unique final state with a downward polarization is obtained, whatever the initial state is $\mathrm{P}_{u p}$ or $\mathrm{P}_{\text {down }}$. This initial configuration has no influence on the values of the local polarization in the final state. That means that water is able to reverse the polarization of the whole ultrathin film, as it has been recently evidenced experimentally 


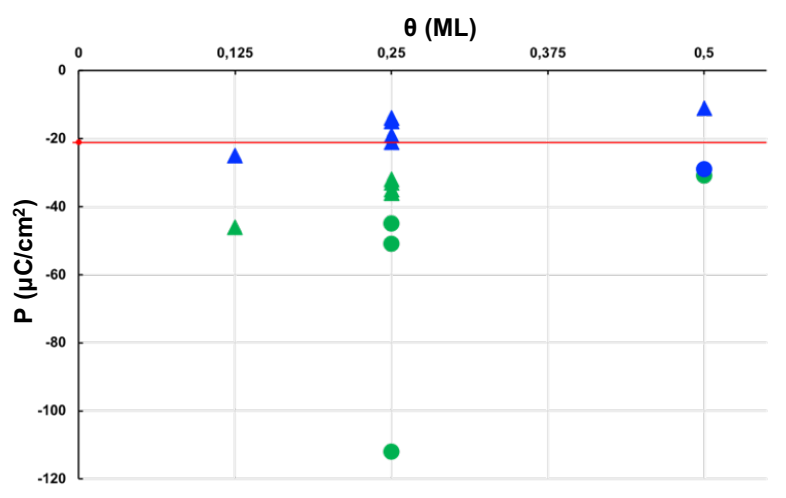

Figure 10. Graphical representation of the local polarization (in $\mu \mathrm{C} . \mathrm{cm}^{-2}$ ) in the upper cell (in contact with either water or vacuum) for different coverage ranging from $1 / 8$ to $1 / 2 \mathrm{ML}$. Blue marks correspond to cases where $\mathrm{H}_{2} \mathrm{O}$ is adsorbed in Mode 1, while for green ones, water is adsorbed on Mode 2. For triangles, only one water molecule is adsorbed per unit cell, while for circles two water molecules are interacting. Corresponding structures are reported in Figures 2, 3, 4, 5, and 6, The red line corresponds to the reference system $\mathrm{BaO}$ polarized downward without $\mathrm{H}_{2} \mathrm{O}$.

for $\mathrm{BiFeO}_{3}$. . More importantly, this result can be used to control the polarization. In fact, by synthesising ultrathin films of BTO with an excess of $\mathrm{Ba}$, one will obtain the $\mathrm{BaO}$ termination and thus, in a humid environment a sample that will be polarized downward, and conversely with an excess of Ti.

Following this important result, the polarization is now analyzed in details.

\section{BaO termination}

As mentioned previously, $\mathrm{H}_{2} \mathrm{O}$ always adsorbs dissociatively on the $\mathrm{BaO}$ termination and stabilizes the downward polarization regardless of the initial state. Water is thus able to switch an initial upward polarization to a downward pointing polarization on $\mathrm{BaO}$ termination. However, even if the polarization is always downward with water adsorbed on the $\mathrm{BaO}$ termination, specific behavior can be evidenced depending on the adsorption mode. To help the discussion, the local out-of-plane polarization of the upper cell, namely the cell in contact with vacuum or water, for each adsorption modes reported on Figures 2 to 6 is plotted on Figure 10, together with the downward polarized bare $\mathrm{BaO}$ termination, used as a reference. 
One can first comment on the global distribution of blue and green marks, Mode 1 and Mode 2, respectively. According to this graph, adsorption Mode 1 and Mode 2 present two distinct behavior. Whatever the periodicity and the total number of water molecules in the simulation cell, adsorption in Mode 2 (green circles and triangles) leads to an increase of polarization in the upper cell, compared to bare $\mathrm{BaO}$. On the contrary, when $\mathrm{H}_{2} \mathrm{O}$ adsorbs in Mode 1 (blue circles and triangles), the local polarization is either kept or lowered compared to BTO without $\mathrm{H}_{2} \mathrm{O}$. This evolution of the polarization can be directly linked to surface bondings. Indeed, for $\theta=1 / 4 \mathrm{ML}$ with $\mathrm{N}=2$ (Figure 3), in Mode 2, the dissociated $\mathrm{OH}$ fragment pulls out the Ba atom by $0.26 \AA$ from the surface, while the surface O bound to the $\mathrm{H}$ fragment is pushed by $0.17 \AA$ in the surface. As a consequence of these surface distortions, the Ti-O bond of the upper cell is elongated. On the contrary, in Mode 1 no particular distortion is observed in the first layer and the bare $\mathrm{BaO}$ polarization is kept. Beyond the out-of-plane polarization, water adsorption also induces modification of the in-plane polarization. One can first comment on cases with only one water molecule per unit cell (triangles on Figure 10). Again both Modes 1 and 2 let different imprints. Starting from an initial state without in-plane polarization, adsorption of water induces an in-plane polarization, pinned by the orientation of $\mathrm{OH}$ groups. When the water molecule adsorbs in the (010) plane (Mode 2), an in-plane polarization arises along the [100] direction. On the contrary, for adsorption in Mode 1, a small polarization appears along the [010] direction. Finally, if we compare $\mathbf{P}$ along [100], [010] and [001], for the different periodicities reported on Figures 2, 3, and 6, differences are only observed between the periodicities $\mathrm{N}=2$ and $\mathrm{N}=4$. Indeed, while no polarization is observed along [100] for Mode 1 for the 2 unit cell periodicity (Figures 3 and 6), a component along [100] appears for the 4 unit cell periodicity (Figures 2 and 4), induced by the enlargement of the domain size as it was already observed ${ }^{32 \mid 36}$. The effect is enhanced when water adsorbs in the [100] direction. Nevertheless the in-plane polarization is still clearly pinned by the orientation of $\mathrm{OH}$ groups.

We can now focus on cases with two water molecules interacting, namely circles on Figure 10. The presence of two interacting molecules induces new behaviors. First of all, for a given coverage and Mode, the presence of a second water molecule increases the outof-plane polarization. This can be easily understood: the second molecule creates hydrogen bond with the first one, pulling it even more out of the surface. Hence, effects described 
previously with one water molecule are intensified. We first consider the $A_{1 / 2}^{2}$ configuration. In this case, the first molecule adsorbs dissociatively but neither in Mode 1, nor in Mode 2 , while the second water molecule is chemisorbed molecularly. This leads to an out-ofplane polarization similar to the one observed without $\mathrm{H}_{2} \mathrm{O}$ (see Figure 10). Besides, a small polarization appears along [010], but in the reverse direction compared to the one observed with Mode 1. This modification is fully consistent with the orientation of $\mathrm{OH}$ groups, opposite to that of Mode 1.

The $B_{1 / 2}^{2}$ configuration also corresponds to one dissociated and one non dissociated water molecule. The dissociated molecule is almost along the [010] direction as observed for Mode 2. In agreement with this orientation, the polarization along [001] is increased compared to the one of the bare surface. An in-plane polarization appears along the [100] direction, but a bit decreased compared to that in Mode 2, while a small polarization emerges along the [010] direction. This can be explained by the orientation of the $\mathrm{OH}$ group. Indeed, compared to pure Mode 2, without a second molecule, $\mathrm{OH}$ is not perfectly aligned but is slightly deviated from the [010] direction, because of the hydrogen bond with the second molecule.

Finally, the last case for $\theta=1 / 2 \mathrm{ML}\left(B_{1 / 2}^{2}\right)$ is composed of two molecules each one being adsorbed on a different unit cell. The neutral polarization of the whole simulation cell is almost preserved with the dissociated molecule adsorbed on a downward polarized cell and the non dissociated physisorbed on a upward polarized cell. This repartition of adsorption configurations is consistent with polarization. Indeed, the larger dissociative adsorption leads to downward polarization. The dissociated water molecule presents a Mode 1 configuration, as a consequence a lower out-of-plane polarization is observed compared to bare BTO and an in-plane polarization appears along the [100] direction.

\section{2. $\mathrm{TiO}_{2}$}

As mentioned previously, we demonstrate that, on out-of-plane polarized $\mathrm{TiO}_{2}$ terminated BTO, the adsorption leads to upward polarization independently of the initial polarization. This polarization switching on the $\mathrm{TiO}_{2}$ termination was suggested by LEED I-V experiments in a previous study 37 . Additionally, Tian et al. studied the polarization switching caused by water adsorption on $\mathrm{BiFeO}_{3}$ thin films with a $\mathrm{FeO}_{2}$ termination ${ }^{19}$. They 


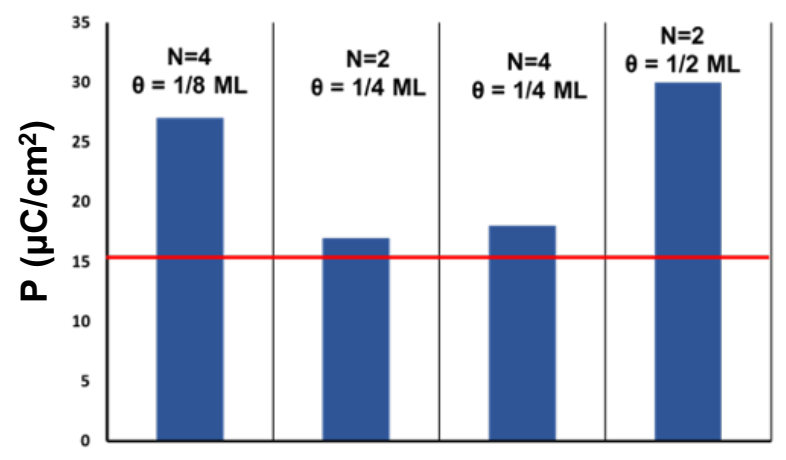

Figure 11. Graphical representation of the local polarization (in $\mu \mathrm{C} . \mathrm{cm}^{-2}$ ) of the upper cell for coverage $1 / 8 \mathrm{ML}$ with $\mathrm{N}=4$, for coverage $1 / 4 \mathrm{ML}$ with $\mathrm{N}=2$ and $\mathrm{N}=4$ and for coverage $1 / 2 \mathrm{ML}$ with $\mathrm{N}=2$ with both molecules in the same unit cell. The red line corresponds to the reference system $\mathrm{TiO}_{2}$ polarized upward without $\mathrm{H}_{2} \mathrm{O}$.

also demonstrated by means of PFM measurements that water shifted the downward polarization to an upward polarization in the whole film. Therefore, our theoretical findings demonstrating that the adsorption of water on the $\mathrm{TiO}_{2}$ termination induces an upward polarized state in a BTO ultrathin film fully agrees with previous experiments. Furthermore, in our calculations a polarization along both [100] and [010] is found in the first surface layers for all periodicities. This in-plane polarization does not exist for bare BTO, whatever the periodicity along [010] and exists only for $\mathrm{N}=4$ along [100], but in a lower extent. Thus the in-plane polarization is clearly induced by the presence of water. Besides, this is qualitatively consistent with previous results obtained by Geneste and Dkhil ${ }^{20}$, even if a quantitative comparison is not straightforward given the differences of coverage.

Let us now focus on the out-of-plane polarization. According to Figure 11, the presence of $\mathrm{H}_{2} \mathrm{O}$ keeps or increases the polarization along [001]. Both the appearance of an in-plane polarization and the evolution of the out-of-plane polarization are directly related to the way the water molecule adsorbs. Indeed, the bonding between the oxygen of the water molecule and the Ti pulls the Ti out of the surface up to $0.1 \AA$, while the highest value observed without $\mathrm{H}_{2} \mathrm{O}$ is $0.03 \AA$ for $\mathrm{N}=4$. As a consequence the Ti-O bond of the first cell is elongated, increasing the upward polarization in this cell. Besides, the water molecule is tilted and creates a hydrogen bond with a surface oxygen. This bond sets the $\mathrm{H}_{2} \mathrm{O}$ orientation and thus the polarization imprint.

Finally, one can comment on the dissociated case (see Figure 91). As mentioned in the previ- 
ous part, the dissociation of water induces a very large interaction between the $\mathrm{OH}$ fragment and the Ti atom of the first layer. As a consequence, this creates a large Ti-O bond in the first cell and thus a very important upward polarization. The out-of-plane polarization is not the only one to be affected by the water dissociation. After dissociation, both $\mathrm{OH}$ fragments are oriented along the [010] direction, creating a rather large polarization along [010] of -26 $\mu \mathrm{C} . \mathrm{cm}^{-2}$. In the same time, the large interaction of dissociated water with the surface also induces distortions of the first layer (see top view on Figure 9 ) creating a polarization in the [100] direction, while this polarization is normally null for the bare $\mathrm{TiO}_{2}$-terminated $\mathrm{BTO}$ with $\mathrm{N}=2$.

\section{CONCLUSION}

The adsorption of water on out-of-plane polarized $\mathrm{BaTiO}_{3}$ ultrathin films is studied by means of DFT calculations. The influence of the surface termination, the water coverage as well as the polarization direction are analyzed. We show that water spontaneously dissociates on the $\mathrm{BaO}$-terminated surface and that it stabilizes downward polarized domains regardless of the initial polarization. Besides, the out-of-plane polarization reinforces the interaction of $\mathrm{BaO}$ towards water. Indeed, contrary to previous results on in-plane polarized BTO, only dissociative adsorption, with higher adsorption energy, is observed. On the $\mathrm{TiO}_{2}$, water does not dissociate spontaneously. However, both the large adsorption energy of dissociated water and the rather small barrier for dissociation tend to indicate, that the dissociated case will be the most probable in real conditions. However, whatever the nature of the adsorption, the interaction of water with the $\mathrm{TiO}_{2}$ termination always leads to domains with an upward polarization. Hence, we demonstrated that in any cases the presence of water is able to induce a given polarization according to the termination of the ultrathin film. As it is known that the reactivity of a ferroelectric material is strongly linked to its polarization direction, one could imagine to favor a specific reaction by tuning the surface termination. 


\section{ACKNOWLEDGMENTS}

Calculations were performed using HPC resources from DNUM CCUB (Centre de Calcul de l'Université de Bourgogne). The authors also thank the ANR for financial support through project ANR-15-CE05-PHOTO-POT and project ANR-17-EURE-0002 (EIPHI Graduate School).

* celine.dupont@u-bourgogne.fr

1 D. Tiwari and S. Dunn, J. Mater. Sci. 44, 5063 (2009).

2 L. Li, P. A. Salvador, and G. S. Rohrer, Nanoscale 6, 24 (2014).

3 A. Kakekhani, S. Ismail-Beigi, and E. I. Altman, Surf. Sci. 650, 302 (2016).

4 M. A. Kahn, M. A. Nadeem, and H. Idriss, Surf. Sci. Rep. 71, 1 (2016).

5 Y. Yun, L. Kampschulte, M. Li, D. Liao, and E. I. Altman, J. Phys. Chem. C 111, 13951 (2007).

6 J. Garra, J. M. Vohs, and D. A. Bonnell, Surf. Sci. 603, 1106 (2009).

7 S. Sanna, R. Hölscher, and S. W. G., Phys. Rev. B 686, 205407 (2012).

8 R. Hölscher, S. Sanna, and W. G. Schmidt, Phys. Status Solidi C 9, 1361 (2012).

9 D. Li, M. H. Zhao, J. Garra, A. M. Kolpak, A. M. Rappe, D. A. Bonnell, and J. M. Vohs, Nat. Mater. 7, 473 (2008).

10 M. H. Zhao, D. A. Bonnell, and J. M. Vohs, Surf. Sci. 7, 473 (2008).

11 M. H. Zhao, D. A. Bonnell, and J. M. Vohs, Surf. Sci. 603, 284 (2009).

12 K. Garrity, A. Kakekhani, A. Kolpak, and S. Ismail-Beigi, Phys. Rev. B 88, 045401 (2013).

13 A. Kakekhani and S. Ismail-Beigi, ACS Catal. 5, 4537 (2015).

14 R. V. Wang, D. D. Fong, F. Jiang, M. J. Highland, P. H. Fuoss, C. Thompson, A. M. Kolpak, J. A. Eastman, S. K. Streiter, A. M. Rappe, and G. B. Stephenson, Phys. Rev. B 102, 047601 (2009).

15 J. Shin, V. B. Nascimento, G. Geneste, J. Rundgren, E. W. Plummer, B. Dkhil, S. V. Kalinin, and A. P. Baddorf, Nano Lett. 9, 3720 (2009).

16 D. Y. He, L. J. Qiao, A. A. Volinsky, Y. Bai, M. Wu, and W. Y. Chu, Appl. Phys. Lett. 98, $98(2011)$. 
17 H. Lee, T. H. Kim, J. J. Patzner, H. Lu, J. W. Lee, H. Zhou, W. Chang, M. K. Mahanthappa, E. Y. Tsymbal, A. Gruverman, and C. B. Eom, Nano Lett. 16, 2400 (2016).

18 O. Copie, N. Chevalier, G. Le Rhun, C. L. Rountree, D. Martinotti, S. Gonzalez, C. Mathieu, O. Renault, and N. Barrett, ACS Appl. Mater. Interfaces 9, 29311 (2017).

19 Y. Tian, L. Wei, Q. Zhang, H. Huang, Y. Zhang, H. Zhou, F. Ma, L. Gu, S. Meng, L.-Q. Chen, C.-W. Nan, and J. Zhang, Nat. Commun. 9, 3809 (2018),

20 G. Geneste and B. Dkhil, Phys. Rev. B 79, 235420 (2009).

21 X. Li, B. Wang, T. Y. Zhang, and Y. Su, J. Phys. Chem. C 118, 15910 (2014).

22 X. Li, Y. Bai, B. C. Wang, and Y. J. Su, J. Appl. Phys. 118, 094104 (2015),

23 G. Kresse and J. Furthmüller, Phys. Rev. B 54, 11169 (1996),

24 G. Kresse and J. Furthmüller, Comput. Mater. Sci. 6, 15 (1996)

25 S. Grimme, J. Antony, S. Ehrlich, and H. Krieg, J. Chem. Phys. 132, 154104 (2010).

26 J. P. Perdew, K. Burke, and M. Ernzerhof, Phys. Rev. Lett. 77, 3865 (1996),

27 P. E. Blöchl, Phys. Rev. B 50, 17953 (1994).

28 G. Kresse and D. Joubert, Phys. Rev. B 59, 1758 (1999).

29 J. D. Pack and H. J. Monkhorst, Phys. Rev. B 13, 5188 (1977).

30 H. Guo, L. Liu, Z. Chen, S. Ding, H. Lu, K. Jin, Y. Zhou, and B. Cheng, Europhys. Lett. 73, $110(2006)$.

31 S. Lee, L. Baasandorj, J. Chang, I. Hwang, J. Kim, J. Kim, K. Ko, S. Shim, M. Choi, M. You, C. Yang, J. Kim, and J. Song, Nano Lett. 19, 2243 (2019).

32 P.-M. Deleuze, A. Mahmoud, B. Domenichini, and C. Dupont, Phys. Chem. Chem. Phys. 21, 4367 (2019)

33 M. Sepliarsky, M. G. Stachiotti, and R. L. Migoni, Phys. Rev. Lett. 96, 137603 (2006).

34 J. D. Baniecki, M. Ishii, K. Kurihara, K. Yamanaka, T. Yano, K. Shinozaki, T. Imada, and Y. Kobayash, J. App. Phys. 106, 054109 (2009).

35 G. Henkelman, B. P. Uberuaga, and H. Jonsson, J. Comp. Phys. 113, 9901 (2000).

36 J. Dionot, G. Geneste, C. Mathieu, and N. Barrett, Phys. Rev. B 90, 014107 (2014).

37 J. L. Wang, F. Gaillard, A. Pancotti, B. Gautier, G. Niu, B. Vilquin, V. Pillard, G. L. Rodrigues, and N. Barrett, J. Phys. Chem. C 116, 21802 (2012). 